\title{
DOSSIË
}

Sociologias, Porto Alegre, ano 15, no 32, jan./abr. 2013, p. 52-93

\section{Democratização da Governanç̣a Global: perspectivas históricas mundiais}

\section{Resumo}

Este artigo examina a controversa noção de democracia global. O texto apresenta uma perspectiva histórica mundial da evolução da governança global como a estrutura política do sistema-mundo evoluiu ao longo dos últimos séculos - e analisa movimentos sociais contemporâneos que buscam democratizar as instituições de governança global. Argumenta-se que os que desejam democratizar a governança global devem assumir o repto de ajudar a promover a construção de um estado mundial globalmente multilateral para fazer frente aos desafios que se colocarão à humanidade no século 21. Movimentos sociais transnacionais e estados nacionais semiperiféricos progressistas são vistos como os agentes que irão desafiar os poderes constituídos e conduzir a humanidade rumo a uma comunidade global democrática e coletivamente racional nas próximas décadas.

Palavras-chave: Democracia. Sistemas-mundo. Evolução. Governança global. Eurocentrismo.

\footnotetext{
"Pós Doutor em Sociologia. Professor e Diretor do Instituto de Pesquisas sobre SistemasMundo da Universidade da Califórnia, Riverside. (EUA) E-mail: chriscd@mail.ucr.edu

** Psicólogo Social, Professor Adjunto de Psicologia das universidades Dominicana e Golden Gate, e do Diablo Valley College, Califórnia (EUA). E-mail: goethe48@pacbell.net

${ }^{v}$ Tradução de Regina B. Vargas
} 


\section{Democratizing Global Governance: World historical Perspectives ${ }^{v}$}

\section{Abstract}

This article examines the contested idea of global democracy. It presents a world historical view of the evolution of global governance - how the political structure of the world-system has evolved of over the past several centuries - and it examines contemporary social movements that are seeking to democratize global governance institutions. It is argued that those who want to democratize global governance must take up the problem of helping to further construct a global multilateral world state in order that the challenges that humanity has created for itself may be met in a collectively rational, sustainable and humane manner in the 21st century. Transnational social movements and progressive semiperipheral nationalstates are seen as the agents that will challenge the powers that be and move humanity closer to a democratic and collectively rational global commonwealth in the next several decades.

Keywords: Democracy. World-systems. Evolution. Global governance. Eurocentrism

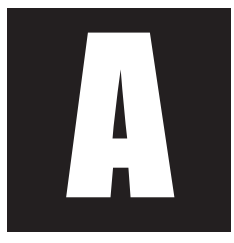

o longo dos últimos séculos, a governança global evoluiu rumo a práticas mais democráticas, como sugerem a abolição da escravidão e do colonialismo formal e o estabelecimento de um sistema de direitos humanos, embora este último só esteja parcialmente institucionalizado e aplicado. O ideal político da democracia, apesar da persistente controvérsia sobre seu significado, tem sido progressivamente adotado pelos povos do mundo, mas as instituições de governança global existentes saem-se mal quando confrontadas, até mesmo, às mais lassas definições de democracia. A maioria das pessoas do planeta tem pouco conhecimento sobre as instituições de governança global existentes. A democracia no âmbito dos estados-nacionais, embora seja um objetivo 
louvável e, em muitos casos, uma conquista inestimável, não conduz à democracia global, pois pouco informa sobre as relações entre estadosnação ou sobre governança na esfera mundial. As atuais instituições de governança global são, em sua maior parte, reflexos dos desfechos da Segunda Grande Guerra.

\section{Definições Controversas de Democracia Global}

Democracia é um conceito controverso tanto em teoria como na prática, mesmo no âmbito nacional (Robinson, 1996). Ainda mais controversa é a ideia de uma democracia global. A maioria dos cientistas políticos não utiliza esta noção para a esfera mundial e, quando algum o faz, traz imediatamente a questão da hegemonia cultural europeia e da relevância da ideia de democracia para as civilizações não europeias. Para muitos, democracia global é simplesmente o somatório de um número crescente de democracias nacionais - regimes representativos em que eleições imparciais escolhem os líderes políticos do estado nacional. Este é o tema mais recorrente na literatura das ciências sociais sobre democratização e constitui o referencial básico da maior parte dos discursos da política mundial quando os estados buscam justificar suas ações apelando para a ideia de democracia. Porém, um número crescente de ativistas transnacionais sustenta que democracia global deveria significar muito mais do que isso. Os povos do mundo vivem em um único sistema social, e as decisões sobre o que acontecerá nesse sistema constituem os principais pontos para se entender o significado de democracia global. Em uma tal democracia, a maioria dos povos da Terra teriam poder de influenciar as decisões que afetam suas vidas. O mero somatório de democracias nacionais não necessariamente conduz à democracia mundial, pois há desigualdade de poder entre os estados nacionais e a questão de uma 
democracia de âmbito global depende significativamente da natureza das relações entre os estados nacionais. Quando os problemas são globais, a democracia deve ser global, o que significa que a maioria dos povos da Terra deveria ser capaz de influenciar significativamente as instituições de governança mundial. Tais instituições desenvolveram-se ao longo dos séculos passados e, sendo assim, uma análise das possibilidades de uma democracia global deve partir do conhecimento da evolução histórica da governança global.

Nossa abordagem coloca em questão a ideia de que democracia representativa em estados isolados leva à democracia global, mesmo quando a maioria dos estados no sistema exibe esse tipo de regime político. Alguns estados detêm muito mais poder do que outros, e suas políticas têm impacto em todo o planeta. Isto é o que denominamos o problema da democracia global vs. democracia de estados individuais.

O segundo foco de nosso ensaio recai sobre a questão da natureza controversa da ideia de democracia. Destaca-se, aqui, que a própria definição de democracia tem sido foco de disputas políticas tanto no contexto do lluminismo europeu como no discurso sobre o eurocentrismo. Buscamos acercar-nos da formulação de um consenso global sobre o sentido da noção de democracia popular. Isso requer o conhecimento dessa história de lutas políticas em todo o planeta e da evolução histórica das sociedades humanas ao longo dos últimos 50 mil anos (Chase-Dunn, 2007).

A literatura sobre democratização tem focado no estudo de como e por que algumas sociedades foram capazes de institucionalizar regimes políticos representativos para a transmissão pacífica do poder por meio de eleições populares. Essa é uma literatura relevante e permite aprender muito sobre as condições que favorecem sistemas representativos estáveis. As recentes sinopse e conclusões de Charles Tilly (2007), baseadas em décadas de estudos da história política de sociedades nacionais, pro- 
porcionam um roteiro útil para análise das condições em que um estado nacional responde à vontade de seus cidadãos. Segundo a análise de Tilly (2007), a democracia, em âmbito nacional, é tênue e de difícil sustentação, mesmo nos estados em que está firmemente institucionalizada. Um estado, destaca ainda esse autor, deve ser capaz de conter a autonomia das elites internas que se opõem ao poder popular (p.ex., a militar). Embora ele mesmo não o faça, a análise de Tilly (2007) pode ser aplicada às questões da formação de um estado global e da democracia global (ver adiante). Tilly (2007) dá pouca ênfase aos fatores "externos" que têm tido importante impacto sobre a democracia nacional, e não trata, no livro citado, das questões suscitadas pela globalização.

Um exame da democracia nacional pela perspectiva do sistemamundo teria, pelo menos, dado conta de que foi o capitalismo central bem sucedido que serviu de apoio à institucionalização de regimes políticos representativos na maioria das sociedades nacionais desenvolvidas. Os países centrais da Europa, os Estados Unidos, Austrália, Canadá, Nova Zelândia e Japão, juntamente com a semiperiférica Índia, são os casos mais bem sucedidos e estáveis de democracia representativa. O resto do mundo tem enfrentado muitas dificuldades para institucionalizar democracias representativas, apesar das repetidas ondas de democratização no sentido parlamentar (Markoff, 1996). Isto se deve, principalmente, à hierárquica divisão do trabalho entre centro e periferia, que concentra a maior parte dos recursos no centro, tornando mais estáveis as alianças entre elites potencialmente rivais e alianças interclasses, por haver um bolo maior a repartir. Na periferia, a luta pelo controle do aparelho de estado, em geral, é mais violenta por ser a única saída. Evidentemente, há exceções, e muitas sociedades nacionais periféricas e semiperiféricas têm conseguido alcançar pelo menos os atributos característicos da democracia parlamentar, especialmente na última onda. 
Não se pretende minimizar as importantes diferenças entre regimes formalmente democráticos, que operam em conformidade com a lei, e regimes autoritários e arbitrários. O alcance da democracia representativa formal e do Estado de direito são ganhos imensos para os povos que não usufruíam destes. Para dar o devido valor aos direitos civis e ao devido processo legal, basta uma visita a qualquer sociedade contemporânea em que as elites locais, com seus próprios instrumentos de coerção, são os principais impositores da ordem social Contudo, vale observar que a democracia representativa formal, mesmo naquelas sociedades em que está mais firmemente institucionalizada, não necessariamente representa o melhor dos mundos.

No discurso iluminista europeu, é antiga a disputa entre as ideias de democracia formal representativa e democracia direta plebiscitária. Bill Robinson (1996) caracteriza "poliarquia" como uma disputa conduzida por elites rivais para legitimar regimes baseados em profundas desigualdades. A definição de democracia predominante no ocidente é aquela que separa direitos políticos de direitos econômicos e que legitima e sustenta a propriedade privada dos principais meios de produção. Versões mais populistas e diretas da ideia de democracia questionam a separação radical entre direitos políticos e econômicos, bem como a exclusão de democracia econômica dos debates. Assim, o tipo de democracia que se tornou hegemônico no sistema-mundo moderno é aquele mais congruente com o capitalismo - um que protege os detentores privados dos principais meios de produção da maior parte das reivindicações sobre sua propriedade e lucros ao definir estritamente um campo de direitos.

A poliarquia debilita a democracia direta e, com base em uma filosofia política estreita, desenvolvida a partir do ramo conservador do discurso iluminista europeu, define certas demandas como externas aos limites do discurso racional. As versões de esquerda - anarquismo, socia- 
lismo e comunismo - foram derrotadas e proclamadas extintas na celebração do "fim da história" e da vitória da democracia racional capitalista.

A crítica ao eurocentrismo também colocou em questão a hegemonia da definição poliárquica de democracia. Muitos dos povos dos impérios coloniais possuíam formas autóctones de regulação política em pequena escala, que possibilitava às pessoas em comunidades locais influírem nas decisões tomadas sobre questões que afetavam suas vidas. Na resistência popular contemporânea ao capitalismo corporativo globalizante, muitas vozes vêm reafirmando a autenticidade e o valor dessas instituições políticas tradicionais (p.ex., Shiva, 2002).

Movimentos congregando pessoas em torno da ideia de autossuficiência comunitária foram respostas frequentes às calamidades da integração do mercado rural que se combinou a secas e escassez de alimentos para produzir os enormes e desastrosos holocaustos vitorianos tardios, durante a grande onda de globalização capitalista de finais do século 19 (Davis, 2001). Esses movimentos autóctones não raro empregavam crenças milenares, as quais previam a volta do bom rei ou a intervenção das forças da natureza para destruir as vias férreas invasoras e os demônios brancos responsáveis por desvirtuar o equilíbrio natural do universo. As pessoas descobriram que podiam produzir seu próprio alimento e diversão sem ter de submeter-se às forças do mercado global e às tecnologias inseguras sobre as quais não tinham controle algum.

Boa parte da crítica pós-colonialista ao eurocentrismo tem por pressuposto que ideologia Iluminista europeia constituiu o principal instrumento da dominação colonial do Terceiro Mundo pelos estados europeus. Assim, as ideologias de direitos, a separação entre igreja e estado, e outros elementos do pensamento europeu foram rejeitados como tantas relíquias da dominação. Não foi a ideologia liberal que causou tanta exploração e dominação. Antes, foi o fracasso do capitalismo real de satisfa- 
zer seus próprios ideais (liberdade e igualdade) na maior parte do mundo. Este é o problema que os progressistas precisam resolver.

A primeira coisa importante a registrar é que a democracia não é uma invenção europeia e tampouco foi monopólio da Europa. A narrativa europeia da democracia como uma invenção das cidades-estado da Grécia clássica é repleta de contradições. A economia da maior parte das cidadesestado gregas era baseada na escravidão (Bollen; Paxton, 1997), enquanto as formas de governo entre os caçadores-coletores nômades, ancestrais de todos os povos da Terra, eram sistemas igualitários em que todos os adultos participavam das decisões coletivas importantes para o grupo.

Ao longo dos últimos doze mil anos, a maioria das regiões da Terra conheceu processos de desenvolvimento de estruturas sociais hierárquicas em que elites vieram a dominar e explorar as massas de camponeses e de trabaIhadores. Porém, a luta por supremacia nunca cessou. Os ciclos de ascensão e queda que caracterizam todos os sistemas hierárquicos derivam, em parte, do conflito básico pelo controle, que é o que disputa a democracia.

Ainda assim, discordamos daqueles que consideram todos os estados igualmente exploradores, embora tampouco concordemos com quem pinta as democracias nacionais contemporâneas como o melhor dos mundos. Hierarquias foram necessárias para harmonizar sociedades cada vez mais amplas e mais complexas, e mesmo sociedades menos hierárquicas (ou menores) tiveram de optar entre erigir suas próprias hierarquias ou perecer na luta com sociedades mais hierárquicas. Portanto, quase todas as sociedades do planeta experimentaram a formação do estado ou foram incorporadas a estados existentes.

Contudo, nem todos os estados são iguais. Há diferenças substanciais entre os estados modernos, relativas ao grau em que os direitos políticos e econômicos são extensivos a todos os cidadãos e à participação da maioria em processos decisórios relevantes. Embora concordando com 
Robinson (2004) em que isso é, em parte, uma farsa, porque legitima o poder das elites capitalistas, é importante assinalar que é melhor a encenação do que nem isso. É pior o caso de um governo assumidamente autoritário e, portanto, trata-se de ajudar aqueles que ainda não usufruem uma poliarquia nacional a alcançá-la e, para os estados em que for possível, avançar além dela. É necessário, também, democratizar a governança global. No âmbito mundial, poliarquia seria preferível à situação atual, em que instituições de governança global apoiam-se na estrutura institucionalizada do sistema inter-governamental para ocultar o verdadeiro poder e autoridade globais.

Também seguimos Robinson (2004) quando este afirma que a poliarquia é frequentemente utilizada para debilitar movimentos mais radicais e democracia direta considerados ameaçadores aos interesses das elites capitalistas. Queremos, uma vez mais, levantar a questão da democracia global e imaginar a possibilidade, no futuro, de uma comunidade global coletivamente racional.

\section{Globalização Capitalista e Governança Global}

Entendemos o desenvolvimento histórico do sistema-mundo moderno em termos da evolução de instituições. Essas instituições chave - produção de mercadorias, tecnologia e técnicas de poder - foram conformadas por lutas entre poderes rivais e entre centro e periferia ao longo dos últimos seis séculos, quando a Europa despontou para a hegemonia global.

A narrativa de como as ordens globais foram reestruturadas de modo a facilitar a acumulação capitalista deve ser feita segundo uma perspectiva temporal alargada para que se possa captar diferenças ou similaridades entre a onda mais recente de globalização corporativa e as ondas de globalização anteriores. De particular relevância, aqui, é o fenômeno das 
revoluções mundiais e dos movimentos anti-sistêmicos crescentemente transnacionais. Para compreenderem-se as possibilidades de emergência de uma democracia global, é preciso conhecer a história dos movimentos populares que tentaram democratizar o sistema-mundo no passado.

\section{Revoluções Mundiais}

A evolução observada com a ascensão e queda dos poderes centrais hegemônicos deve ser vista como uma sucessão de modelos de ordem mundial desenvolvidos para solucionar os problemas técnicos, econômicos e políticos de ondas de acumulação capitalista gradualmente mais globais. A ampliação da produção mundial envolvia o acesso a matérias primas para abastecer as novas indústrias, e a alimentos para nutrir as populações em expansão (Bunker; Ciccantell, 2004). Como, em qualquer hierarquia, a coerção é um meio um tanto ineficiente de dominação, os poderes hegemônicos buscavam legitimar-se proclamando sua liderança na promoção da civilização e da democracia. No entanto, os mesmos termos dessas asserções eram também empregados pelos subordinados que buscavam proteger-se da exploração e da dominação. Assim, o avanço da hegemonia produziu-se pela competição entre grupos de elite, em um contexto de fortes e sucessivos desafios por parte dos estratos subordinados. As ordens mundiais foram contestadas e reconstruídas em uma série de revoluções mundiais que iniciaram com a Reforma Protestante (Boswell; Chase-Dunn, 2000ª , p. 53-64).

A ideia de revolução mundial é uma noção ampla, que abrange todas as formas de resistência à hierarquia, independentemente do fato de ser ou não coordenada. Geralmente, a noção de revolução é conceitualizada em uma escala nacional em que novas forças sociais alcançam o poder estatal e reestruturam as relações sociais. Quando utilizamos o 
conceito de revolução no âmbito do sistema-mundo, uma série de mudanças é necessária. Não existe (ainda) um estado mundial a conquistar. Mas existe um sistema de governo global - uma ordem mundial - que se desenvolveu conforme já descrito. É esse sistema de governo global ou ordem mundial que constitui a arena em que têm ocorrido as revoluções mundiais e a qual tais revoluções têm reestruturado.

Boswell e Chase-Dunn (2000b) focalizam essas constelações de revoltas e revoluções locais, regionais, nacionais e transnacionais que tiveram impactos de longo prazo na transformação de ordens mundiais. Ordens mundiais são aquelas características institucionais e normativas incontestes em circunstâncias de cooperação, concorrência e conflito em larga escala. Os anos que marcam as principais revoluções mundiais após a Reforma Protestante são: 1789, 1848, 1917, 1968 e 1989. Pode-se afirmar, plausivelmente, que outra se encontra, hoje, em processo de fermentação. Arrighi, Hopkins e Wallerstein (1989) analisaram as revoluções mundiais de 1848, 1917, 1968 e 1989. Esses autores sustentam que as reivindicações colocadas em uma revolução mundial, em geral, não se institucionalizam até que uma revolta de consolidação tenha ocorrido, ou até a próxima revolução mundial. Assim, os revolucionários parecem ter perdido em vista do fracasso de suas demandas mais radicais, mas conservadores liberais que tentam administrar a hegemonia acabam incorporando as reformas que antes constituíam demandas radicais à ordem mundial vigente.

Importa, aqui, destacar a história do século 19 e seu tsunami de globalização capitalista, sob os auspícios da hegemonia britânica. Movimentos transnacionais anti-sistêmicos, especialmente o movimento sindicalista e o movimento feminista, emergiram para combater o capitalismo global. Os trabalhadores e as mulheres assumiram conscientemente o papel de cidadãos/cidadãs do mundo, organizando movimentos internacionais 
para confrontar a crescente organização global de uma classe capitalista mundial emergente. Elites políticas e econômicas, em especial os capitalistas financeiros, já vinham operando deliberadamente, há séculos, em âmbito global, mas seu grau de integração internacional elevou-se muito ao final do século 19. Na Europa, os britânicos haviam criado o "Concerto da Europa" pós-Napoleônico, uma aliança de dinastias e políticos conservadores que se dedicava a prevenir futuras revoluções na França.

A Marinha Real Britânica extinguiu o tráfico de escravos e incentivou a descolonização das colônias espanholas. A promoção, por parte da Liga Inglesa contra as Leis de Cereais (Anti-Corn Law League), do livre comércio internacional (difundido no exterior por diplomatas e empresários britânicos) teve a adesão da maioria das nações da Europa e das Américas em meados do século. O padrão ouro constituiu uma base importante para a enorme expansão do comércio e do investimento internacionais (Chase-Dunn; Kawano; Brewer, 2000; O'Rourke; Williamson 1999). A expansão da economia atlântica, já firmemente unida ao Oceano Índico, foi acompanhada da expansão da economia pacífica, à medida que Japão e China iam incorporando-se de forma mais direta e integral às redes de comércio e investimento da Europa e da América dos Norte. O ginseng americano era cultivado nos estados da região do Médio Atlântico (EUA) como um importante insumo básico que podia ser trocado por produtos manufaturados chineses, sem ter de recorrer a pagamento em prata.

O sucesso desta onda de globalização capitalista não ficou totalmente incontestado.

Emergiram com força, na Europa, no contexto da revolução mundial de 1848, demandas socialistas e democráticas por direitos econômicos e políticos para as classes desprivilegiadas e para as mulheres. A descolonização da América Latina estendeu os aspectos formais da soberania de estado a uma grande parte da periferia. Revoltas de escravos, abolicionis- 
mo e a incorporação da África ao sistema-mundo capitalista conduziram, por fim, à abolição da escravidão em quase todo o mundo.

\section{Desenvolvimento da Semiperiferia}

Um aspecto importante de nosso modelo de evolução do sistemamundo é a ideia de desenvolvimento da semiperiferia. Observamos que o desenvolvimento institucional nos sistemas-mundo pré-modernos ocorreu, muitas vezes, em razão do surgimento de inovações e da implementação de novas técnicas e formas de organização em sociedades que se encontravam em posições semiperiféricas no âmbito das amplas hierarquias centro/periferia (Chase-Dunn; Hall, 1997, cap. 5). Assim, domínios semiperiféricos fronteiriços conquistavam outras comunidades autônomas centrais mais antigas para criar domínios supremos mais extensos (Kirch, 1984). E estados semiperiféricos fronteiriços (marcher states) conquistavam estados centrais adjacentes para criar impérios centrais mais extensos (core-wide) (p.ex. Chinês, Mesopotâmico, Assírio, Persa Aquemênida, Macedônico, Romano, Califado Abássida etc.) Além disso, cidades-estado capitalistas semiperiféricas (Dilmun, Tiro fenícia, Sídon, Cartago, Veneza, Gênova, Malaca etc.) expandiam as redes de comércio e estimulavam a produção de insumos básicos [e o comércio] entre impérios afluentes e regiões periféricas, conectando regiões cada vez maiores para, finalmente, chegar à economia global hoje consolidada. Os poderes hegemônicos da era moderna (a República Holandesa do século 17, o Reino Unido da Grã Bretanha no século 19, e os Estados Unidos da América no século 20 foram todos, anteriormente, estados-nação semiperiféricos que se elevaram à posição de hegemonia. A esta chegaram, por mudar as bases institucionais do poder político/militar e econômico, em resposta tanto à disputa pela hegemonia por parte de adversários como às revoltas e 
revoluções realizadas por movimentos populares contra as injustiças do imperialismo colonial e do capitalismo.

O sistema-mundo moderno experimentou ondas de democracia de alcance sistêmico, ao invés de uma série de casos isolados de democratização de países (Markoff, 1996). Essas ondas tenderam a ter início em países semiperiféricos e as invenções institucionais que se difundiram de um país para outro foram majoritariamente criadas e implementadas, primeiro, nesses países. Os mais fortes desafios ao capitalismo (os estados comunistas) concentraram-se, principalmente, na semiperiferia.

O movimento de trabalhadores tornou-se gradualmente mais organizado no âmbito internacional, durante o século 19. Os organizadores conseguiram tirar proveito de meios de transporte mais rápidos e baratos, bem como dos novos meios de comunicação (o telégrafo), para conectar as lutas entre lugares distantes. Além disso, a intensa migração de trabaIhadores da Europa para o Novo Mundo disseminou as ideias e as estratégias do movimento trabalhista. Socialistas, anarquistas e comunistas confrontaram o domínio do capital enquanto disputavam entre si pela liderança de um movimento anti-sistêmico progressivamente mundial que buscava democratizar o sistema-mundo.

\section{A Democracia Direta dos Conselhos de Trabalhadores}

Nos últimos 130 anos, uma série de esforços para instituir democracia direta - sem capitalistas, o Estado ou um partido de vanguarda leninista - tem irrompido no calor das crises nacionais. Em alguns casos, esses "conselhos de trabalhadores" emergiram juntamente com o Estado, criando uma situação de "duplo governo". Durante a revolução espanhola, de 1936 a 1939, os conselhos de trabalhadores se disseminaram amplamente, atingindo cerca de um terço do país. Tais conselhos não só 
governavam sem o Estado como também, por vezes, aboliram as moedas locais e deram início a novos sistemas de troca. Essas experiências tiveram lugar durante períodos revolucionários, quando as autoridades oficiais haviam perdido poder. Contudo, tais eventos de democracia direta popular, quase sempre, foram breves. A greve geral de Seattle, por exemplo, foi uma questão de poucos dias, embora o caso espanhol de duplo governo tenha durado três anos.

Como a maioria dos movimentos sociais, esses conselhos surgiram simplesmente como reação aos abusos do poder vigente. Os trabalhadores demandavam melhores salários, melhores condições de trabalho e mais justiça. Mas, tendo as autoridades perdido o poder, aqueles viam-se fazendo muito mais do haviam previsto. Os conselhos de trabalhadores eram inventivos e festivos, produzindo novas formas de organização coletiva. Na Espanha, após a fracassada tentativa de golpe de Franco, pelo menos um terço das empresas do país ficou sob autogestão dos trabalhadores. A maior parte das firmas dirigidas pelos trabalhadores alcançou índices mais altos de produção do que exibiam antes do golpe, apesar das condições caóticas da guerra civil.

As formas organizacionais que emergiram nos conselhos de trabalhadores revelavam boa dose de criatividade com relação a modelos democráticos de governança econômica. A organização central dos conselhos, o principal órgão de tomada de decisão, era a assembleia geral. As resoluções das assembleias gerais eram efetivadas por delegados com mandato, os quais não detinham autoridade independente (o que difere de representantes que, uma vez eleitos, têm poder para tomar suas próprias decisões). Esses delegados eram instruídos a implementar as decisões tomadas em assembleia. Além disso, havia um rodízio frequente de delegados, de modo a que ninguém pudesse se acomodar à condição de autoridade. Por fim, a condição de delegado podia ser prontamente revogada. Qualquer abuso de poder seria razão para a imediata destituição do 
cargo. Não havia qualquer procedimento burocrático que pudesse atrasar a substituição de um delegado que abusasse do poder.

Conselhos de trabalhadores surgiram nas seguintes épocas e localidades:

- A Comuna de Paris de 1871

- O Soviete de São Petersburgo de 1905

- A Revolução Russa de 1917

- Tentativas de curta existência na Polônia, Itália, Alemanha e Bulgária, entre 1917 e 1920

- A Greve Geral de Seattle de 1919

- A Revolução Espanhola de 1936 (durante a maior parte do primei-

ro ano e, depois, de forma intermitente até 1939)

- A Revolução Húngara de 1956

- A Greve Geral da França de 1968

- A Revolução Chilena de 1970-1973

- Os comitês de Fábrica na Argentina e na Venezuela e os conselhos de trabalhadores rurais do Brasil nas últimas duas décadas

- O movimento de Ocupação (Occupy Movement) que irrompeu no outono de 2011

\section{A Evolução da Governança Global}

Concebeu-se um sistema de governo global que há muito está composto por estados nacionais em que as elites têm desempenhado as funções de relações internacionais, mas o qual está, gradualmente, se transformando em uma arena de participação popular direta. Tecnologias de comunicação global de baixo custo aceleraram uma tendência de formação de movimentos sociais transnacionais cujas raízes estão nos séculos precedentes. Ideias de democracia firmemente institucionalizadas nas sociedades modernas vêm sendo aplicadas de forma crescente em âmbito mundial. Tanto as elites formuladoras de políticas como os movimentos sociais transnacionais começaram a questionar a natureza democrática das instituições de governança global existentes. 
A noção de sociedade civil global idealiza uma população humana, de toda a Terra, informada sobre os problemas de escala mundial, e visualiza ações para solucioná-los. Embora os movimentos sociais transnacionais - neles compreendidos os religiosos e os seculares - venham, há muito, contestando as estruturas institucionais de governança global, a participação de grandes contingentes de não-privilegiados (non-elites) expandiu-se de modo acentuado no movimento contemporâneo por justiça global. Manifestações de protesto perante o G-8, o Banco Mundial, a Organização do Tratado do Atlântico Norte, o Fundo Monetário Internacional e a Organização Mundial do Comércio tornaram-se frequentes, e centenas de milhares de pessoas de todos os continentes têm comparecido aos encontros do Fórum Social Mundial. Esta explosão de cidadania global tem sido facilitada pela Internet, pois movimentos locais facilmente tornam-se nacionais e, logo, transnacionais, para confrontar problemas que parecem não ter solução na esfera local ou nacional.

A terminologia "relações Norte-Sul" passou a designar o tipo de relações que se estabelecem entre os países ricos e poderosos e aqueles pobres e menos desenvolvidos (Reuveny; Thompson, 2008). Preferimos os termos centro (core), periferia e semiperiferia definidos como posições estruturais dentro de uma hierarquia global, a qual é, simultaneamente, econômica, política-militar e cultural. A hierarquia centro-periferia no âmbito global, embora organizada espacialmente, não envolve uma simples questão de latitude, como sugere a terminologia Norte-Sul. Antes, constitui uma hierarquia complexa e multidimensional, de distintas formas de relações de poder e de dependência inter-relacionadas.

Governança global sempre significou "relações internacionais" - as interações econômicas, políticas, militares e culturais entre um grande número de estados soberanos. Este é o sistema político que se institucionalizou na Europa, com a Paz de Vestfália, em 1648, e que subsequente- 
mente disseminou-se por todo o mundo, quando o sistema de impérios coloniais transformou-se em um sistema interestatal planetário. O sistema de estados soberanos nunca foi, estritamente, um sistema anárquico de competição e conflito. A governança assumiu a forma de liderança e de dominação por parte de uma sucessão de nações poderosas - as hegemônicas - e de seus aliados, embora a hegemonia fosse intermitente. Durante os períodos de disputa hegemônica, o sistema interestatal passava a assemelhar-se ao modelo da anarquia inscrito em muitas teorias de relações internacionais. O modelo dos ciclos sistêmicos de acumulação, desenvolvido por Giovanni Arrighi (1994, 2007) analisa a evolução da governança global através de uma sucessão de hegemonias. Como aponta Arrighi (2007, p. 166), [...] nações hegemônicas desempenham funções governamentais na esfera global [...].

O sistema interestatal e a ascensão e queda de poderes centrais hegemônicos passou por mudanças ao longo dos últimos duzentos anos (desde o fim das guerras napoleônicas), em função do surgimento de organizações internacionais que operam entre e por sobre os estados nacionais (Murphy 1994; Boli; Thomas, 1999). Tal emergência de instituições multilaterais tem sido chamada de "globalização política", e é vista como possível precursora da eventual formação de um estado mundial (Chase-Dunn; Inoue; Alvarez; Niemeyer, 2008). Saskia Sassen (2007) e Bill Robinson (2004) também analisaram as formas pelas quais as nações se reconfiguraram nas últimas décadas do século 20, para servirem como instrumentos de uma emergente classe capitalista transnacional. Assim, a governança global estrutura-se como um sistema de estados nacionais aliados e rivais, de ascensão e queda de poderes hegemônicos, e de um sistema cada vez mais denso de instituições públicas e privadas de escala internacional e transnacional. 
Disputas por hegemonia e guerras mundiais têm sido o principal mecanismo de "escolha" das lideranças mundiais (Modelski; Thompson, 1996). Este método primitivo de reparar as consequências do desenvolvimento desigual é o que necessita ser substituído por uma forma de governança global que logre resolver conflitos pacificamente. Há quem considere que isto já foi alcançado com o surgimento de instituições multilaterais de governança mundial. Outros temem que tais instituições não sejam fortes o suficiente para resistir à tormenta de uma nova rodada de disputa hegemônica.

Atualmente, as principais instituições públicas de governança global são o governo dos Estados Unidos (o poder hegemônico hoje em declínio, embora ainda um superpoder militar), a Organização das Nações Unidas, o Grupo das 8 mais poderosas economias nacionais (G8), e as instituições financeiras internacionais que foram fundadas quando da Conferência de Bretton Woods, em 1944 (o Banco Mundial, o Fundo Monetário Internacional e a Organização Mundial do Comércio). As principais instituições não públicas são as grandes corporações transnacionais, e as ONGs e organizações de movimentos sociais que desenvolvem ação política em escala global. A governança global contemporânea é conformada por complexas interações entre essas instituições nacionais, internacionais e transnacionais, bem como pelas ONGs transnacionais, pelas empresas e por outros atores não estatais (p.ex., organizações transnacionais de movimentos sociais). ONGs e movimentos sociais transnacionais emergiram, pela primeira vez, no século 19. Seu número e a dimensão de seus quadros de afiliados tiveram grande crescimento nas décadas que se seguiram à Segunda Guerra Mundial (Tarrow 2005; Smith 2008). 


\section{Ondas de Globalização}

O declínio da hegemonia britânica e o fracasso dos esforços posteriores à Primeira Grande Guerra para erigir uma estrutura efetiva de governança global levaram ao colapso da globalização capitalista durante a depressão dos anos 1930 e culminaram na Segunda Guerra Mundial. A nosso ver, a globalização capitalista é tanto um ciclo como uma tendência. A grande onda do século 19 foi seguida de um colapso, ao início do século 20, e do ressurgimento, no período pós Segunda Guerra. As instituições globais da ordem posterior à II Grande Guerra, agora sob o respaldo dos Estados Unidos - o novo poder hegemônico - foram concebidas para resolver os problemas que se acreditava terem sido a causa dos confrontos militares e dos desastres econômicos de inícios do século 20. As Nações Unidas eram uma versão mais forte de um proto-estado mundial do que o fora a Liga das Nações, embora ainda muito distante do "monopólio da violência legítima" que constitui a essência de um verdadeiro estado. As instituições de Bretton Woods - o Banco Mundial e o Fundo Monetário Internacional - foram concebidas para promover o desenvolvimento nacional keynesiano e não um mercado globalizado de fluxos de investimentos. O livre comércio era estimulado, mas os principais esforços focavam no rastreamento dos investimentos internacionais e na estabilização das moedas nacionais. Os arquitetos das instituições de Bretton Woods fora cautelosos em relação aos efeitos de ondas voláteis de fluxos de capital internacional sobre o desenvolvimento econômico, em razão do que consideravam terem sido as lições dos anos 1920. O reinício da economia mundial após a II Grande Guerra, sob a égide das instituições de Bretton Woods e o apoio dos EUA para um capitalismo relativamente autônomo na Europa e no Japão, foi um tremendo sucesso. Mas o poder crescente dos sindicatos no centro, e as restrições impostas pelo regime monetário de Bretton Woods aos interesses financeiros nor- 
te-americanos, juntamente com a crise do petróleo do início da década de 1970, levaram os EUA a abandonar Bretton Woods em favor de um mercado mundial livre para a mobilidade do capital. O "Consenso de Washington" foi, basicamente, reaganismo-thatcherismo em escala global - desregulamentação, privatização e descumprimento do "contrato social" com os principais sindicatos e com o estado de bem estar social. O FMI transformou-se em instrumento de imposição dessas políticas a países do mundo todo.

Esse regime neoliberal de capitalismo global conduzido pelos EUA/ Reino Unido foi uma reação aos êxitos do Terceiro Mundo e dos principais movimentos trabalhistas, não em alcançar efetiva democracia global, mas em conquistar uma considerável fatia dos lucros do capitalismo global. O ataque às instituições de desenvolvimento nacional keynesiano (sindicatos e sistema de proteção social) foi também uma resposta tardia à revolução mundial de 1968, em que estudantes, mulheres, ambientalistas, terceiromundistas, povos indígenas, movimentos democráticos e alas radicais do movimento trabalhista criticaram e opuseram resistência ao capitalismo do bem-estar social e ao sindicalismo de negócios da esquerda. A nova direita apropriou-se de parte da ideologia e de muitas das táticas dos rebeldes de 68 - manifestações, desobediência civil, exércitos de guerrilha, financiamento de drogas, mobilização de grupos separatistas etc. Essas táticas voltaram a inquietar os poderes constituídos. Em recente onda de efeitos adversos, algumas das organizações e ideologias antes apoiadas pela norteamericana C.I.A. como instrumentos contra a União Soviética (a Al-Qaeda, por ex.) voltaram-se contra seus antigos patrocinadores, e empregaram estratagemas vis para atacar os símbolos do poder global e assassinar espectadores inocentes no coração do centro (Johnson 2000).

Acreditamos que o momento histórico atual é similar ao das últimas décadas do século 19. Assim como a hegemonia britânica, então, a hege- 
monia norte-americana está hoje em declínio. Concorrentes em disputa pelo poder econômico mundial surgem na Europa sob liderança alemã e na Ásia liderada pela China. Além disso, a Rússia pós-soviética recusa-se a virar joguete do capital ocidental. Movimentos populares e suas instituições têm sido objetos de crítica, especialmente a partir da escalada da ideologia hegemônica da globalização capitalista neoliberal por quase todo o planeta. Movimentos anti-sistêmicos têm-se esforçado em descobrir novos caminhos para lidar com um capitalismo hegemônico e globalizado. Novas tecnologias de comunicação, especialmente a Internet, parecem facilitar movimentos mais coordenados e integrados em defesa de uma democracia global. As perspectivas emancipatórias de comunicações descentralizadas e democratizadas são grandes. Mas comunicações interativas e de massa baratas também promovem a crescente diferenciação e especialização da mobilização política, o que pode enfraquecer os esforços de coordenação inter-movimentos. Considerados todos os aspectos, sustentamos que a Internet virá a ser uma força emancipatória, embora os grandes ganhos de integração do movimento virão, provavelmente, como resposta aos desastres econômicos, político e ecológicos que o capitalismo globalizado está a produzir hoje e nas décadas vindouras.

Boa parte da resistência contemporânea ao capitalismo global está assumindo a forma de autossuficiência local, de revitalização de diversos modelos culturais e de rejeição de símbolos culturais e tecnológicos do capitalismo corporativo. Assim, a caracterização dos movimentos de protesto por justiça global (Seattle, Gênova etc.) como movimento "antiglobalização", embora se justifique em parte, é enganosa. Autossuficiência pode assumir formas progressistas, mas também formas que promovem cisão entre grupos, com base em etnia, nação ou raça. Autossuficiência, por si só, não é uma estratégia adequada para criar um sistema sociopolítico mais humano e sustentável. Ao invés disso, a construção de comuni- 
dades autossuficientes deve vincular-se a um movimento coordenado de "globalização a partir da base", o qual buscará reformar as instituições de governança global ou substituí-las por outras capazes de promover justiça social e sustentabilidade ambiental.

\section{Concebendo a Democracia Global}

Isto significa formar uma imagem da democracia global. Que forma teria uma tal democracia? E como poderíamos chegar a ela? A democracia global precisa responder a duas questões principais: enormes e crescentes desigualdades tanto internas aos países como entre eles; e graves problemas de sustentabilidade ambiental produzidos pela industrialização, tanto a capitalista como a comunista.

Em lugar de traçar um esboço de uma utopia global, para então discutir os pontos mais significativos, faz mais sentido entender, e aprender com, os esforços anteriores para fazer o que aqui propomos. Utopias podem ser úteis para aqueles que não conseguem imaginar qualquer meIhora possível nas instituições existentes. Mas elas também acabam deslegitimando esforços por produzir mudança social, pois, normalmente, mostram-se inalcançáveis. A abordagem benéfica é imaginar um próximo passo historicamente oportuno, um que seja passível do consenso, entre os públicos relevantes, de que representa uma melhora sensível e de que tem, pelo menos, uma possibilidade de ser alcançado.

Nesse sentido, a ideia deve ser atrativa o suficiente para justificar assumirem-se riscos. Sendo assim, é possível equivocar-se tanto pelo lado da precaução quanto pelo lado da azáfama. Democracia global significa direitos econômicos, políticos e culturais efetivos e poder de voz e voto para a maioria dos povos do mundo sobre as instituições locais e globais que afetam suas vidas. A democracia do estado nacional é apenas uma 
parte da solução. A democracia global requer que os estados nacionais sejam democráticos e que as instituições globais sejam democráticas. Portanto, ela exige instituições democráticas de governança global.

\section{Objeções à Possibilidade de uma Democracia Global}

Autores neodarwinianos como Pierre Van den Berge e psicólogos evolucionistas sustentam que as lealdades familiares e de grupos étnicos são inatas aos humanos, estabelecem-se pela evolução biológica, e que esta se baseia na proximidade genética. Humanos, como outros animais, sempre colocarão suas próprias famílias e grupos étnicos em primeiro lugar. Contudo, um processo intercultural e histórico de socialização muito bem sucedido, que está em andamento há pelo menos 500 anos, tem socializado pessoas para identificarem-se e prestarem lealdade à sua nação. Diz-se de algumas nações que são baseadas no sangue, como famílias e grupos étnicos. Mas outras são construídas em torno da noção de uma história comum.

O nacionalismo é resultado de um longo processo de construção da nação. Hoje, a maioria dos soldados de classe trabalhadora estaria disposta a morrer por seu país. Isto significa que um soldado colocaria sua vida nas mãos de soldados companheiros, quando em batalha - pessoas com quem não tem parentesco e a maioria das quais ele nunca verá outra vez, se saírem vivos do exército. Esses soldados estão lutando por estranhos co-nacionalistas, os quais eles nunca irão encontrar. O poder que o slogan "apoie nossas tropas" possui sobre o americano médio é um excelente indicador do grau de sucesso deste projeto de socialização política. As tropas são, afinal, formadas por estranhos. O processo de como indivíduos são levados a subordinar suas lealdades étnicas, de classe, de região e religiosas a uma ampla comunidade nacional de estranhos é tema de uma vasta literatura sobre construção de nações. 
A existência do nacionalismo como, possivelmente, a mais importante solidariedade socialmente construída no mundo moderno mostra que os psicólogos evolucionistas estão, pelo menos em parte, equivocados. Identificação e comportamento altruísta podem ser reprogramados pelas instituições humanas de modo a que as pessoas venham a identificar-se intensamente e cooperar com estranhos. Isto, porém, não demonstra a ausência de limites à construção social da solidariedade. O fato de que muitas nações possuem significativas similaridades com laços de parentesco e grupos étnicos poderia significar que as afirmações de psicólogos evolucionistas são, pelo menos em parte, verdadeiras (ver Gat, 2006).

Entretanto, em que medida a democracia global exige que os humanos se identifiquem e ajam altruisticamente uns com os outros? É o enteespécie realmente necessário à democracia global? As pessoas precisam amar umas as outras em escala global para que a governança democrática global funcione? Assim como nos estados nacionais, parece que as estruturas institucionais do direito, do devido processo legal, e da autoridade legítima democraticamente responsável perante a maioria poderiam funcionar na ausência de algo como amor global, se as pessoas simplesmente reconhecessem que, para que bilhões de seres humanos possam viver na Terra, são necessários alguns mecanismos coletivos para regular o uso dos recursos naturais e permitir lidar com os problemas de desigualdade global.

Ironicamente, o nacionalismo, que constitui o melhor contra-argumento à perspectiva dos psicólogos evolucionistas, é, de certo modo, um obstáculo à democracia global. É o nacionalismo que possibilita às elites mobilizarem pessoas a lutar umas contra as outras, e os movimentos sociais transnacionais encontram muita dificuldade para superar as divisões nacionais em vista da forte institucionalização dos interesses nacionais. Ulrich Beck (2005) sustenta que o cosmopolitismo baseado no reconhecimento e valorização das diferenças sociais é um dos mais valiosos des- 
fechos da globalização, e que este atributo cultural emergente irá desempenhar um papel importante na democratização de instituições de governança global. O cosmopolitismo é útil aos movimentos sociais que desafiam as cisões oriundas do nacionalismo. Mas, até que ponto se deve avançar politicamente com ele? Isto significa que os cosmopolitas progressistas não deveriam aliar-se e trabalhar com nacionalistas? Deveriam estes últimos ser excluídos das organizações políticas, como sugeriu Warren Wagar (1996). Entendemos que isto seria, certamente, um erro. A globalização não derrotou o nacionalismo e, na verdade, as adversidades econômicas e ambientais que vêm ocorrendo irão revitalizar o nacionalismo, à medida que as pessoas busquem formas de protegerem-se de forças sobre as quais elas têm pouco controle. Excluir os nacionalistas seria, sem dúvida, um equívoco para movimentos que pretendem construir uma democracia global. Assim como em relação aos movimentos localistas e de autossuficiência, a tarefa é encontrar quem se alie a uma estratégia de globalização a partir da base.

\section{O Movimento pela Justiça Global}

Embora, no ocidente, movimentos sociais transnacionais remontem, pelo menos, à Reforma Protestante, a extensão e escala de laços internacionais entre ativistas sociais elevou-se drasticamente ao longo das últimas décadas, pois aqueles passaram a compartilhar, de modo crescente, informação, marcos conceituais e outros recursos, bem como a desenvolver ações coordenadas transpondo fronteiras e continentes (Moghadam, 2005; Reitan, 2007). Nas décadas de 1980 e 1990, o número de organizações transnacionais de movimentos sociais (OTMS) aumentou em quase duzentos por cento. Não obstante a maioria das OTMS ainda estar localizada no norte global, uma parcela crescente delas tem sede ou 
vínculos com o sul do mundo; o número de OTMS com agendas multitemáticas cresceu significativamente, de 43, em 1983, para 161, em 2000 (Smith, Wiest, 2012). Este incremento na organização transnacional subsidiou e auxiliou a criação do movimento pela justiça global. O movimento pela justiça global é um "movimento de movimentos", que inclui todos aqueles envolvidos no contínuo confronto ao capitalismo global neoliberal, propõe estruturas políticas e econômicas alternativas, e mobiliza pessoas pobres e relativamente sem poder. Embora este movimento recorra a formas não institucionais de ação coletiva, não raro, ele coopera com membros ("insiders") institucionais, como ONGs, que desenvolvem ações de lobby e prestam serviços à população, e com formuladores de políticas (Tarrow, 2005, p. 55-56; Keck; Sikkink, 1998). O movimento pela justiça global e seus aliados incluem uma diversidade de atores e grupos sociais: sindicatos, ONGs, OMSs, redes transnacionais de defesa de direitos, bem como formuladores de políticas, acadêmicos, artistas, jornalistas, animadores e outros.

O Fórum Social Mundial (FSM) foi instituído em 2001, como um projeto social contra-hegemônico focalizado em questões de justiça global e democracia ${ }^{1}$. Organizado inicialmente pelo movimento de trabaIhadores brasileiro e pelo movimento dos trabalhadores sem terra, o FSM foi concebido como espaço de encontro de participantes e apoiadores de movimentos de base de todo o mundo, em lugar de uma conferência de representantes de partidos políticos ou governos. O FSM foi organizado como uma alternativa popular ao Fórum Econômico Mundial, uma reunião exclusiva de uma elite de líderes empresarias, políticos e artistas, que ocorre anualmente em Davos, na Suíça. O Fórum Social Mundial foi

\footnotetext{
${ }^{1}$ CARTA de Princípios do Fórum Social Mundial. [S.I.]: Fórum Social Mundial, 2001. Disponível em: <http://www.forumsocialmundial.org.br/main.php?id_menu=4\&cd_language $=1>$. Acesso em: 19 Mar. 2012.
} 
apoiado pelo Partido dos Trabalhadores brasileiro, e foi com mais frequência realizado em Porto Alegre, Brasil, um reduto tradicional daquele partido. Enquanto a primeira reunião do FSM, em 2001, congregou 20.000 participantes inscritos, oriundos de 117 países, o fórum de 2005 reuniu 155.000 inscritos, de 135 países. Este fórum é tanto uma instituição - com suas próprias lideranças, missão e estrutura - como um "espaço aberto" em que uma diversidade de ativistas sociais de todo o mundo reúne-se, troca ideias, participa de eventos multiculturais e coordena ações. O FSM está aberto a todos que se opõem à globalização neoliberal, mas exclui grupos que defendem a resistência armada (Patomaki; Teivainen, 2004). Os participantes distinguem-se em termos de sua filiação a movimentos específicos e diferentes tipos de organizações. Participantes de campanhas locais e nacionais independentes unem-se a veteranos de organizações internacionais e a grupos internacionalmente integrados (Smith; Wiest, 2012). O FSM inspirou a criação de centenas de fóruns sociais locais, nacionais, regionais e temáticos (Byrd 2005; Della Porta 2005).

\section{Questões Norte-Sul}

O foco em justiça social e desigualdades norte-sul, bem com a crítica ao neoliberalismo conferem sólidas diretrizes aos ativistas transnacionais do Fórum Social Mundial. Mas há questões complicadas para a ação coletiva que estão profundamente enraizadas nas imensas desigualdades internacionais prevalentes no sistema-mundo contemporâneo. Nossa pesquisa com os participantes do Fórum Social Mundial de 2005 identificou diferenças significativas entre ativistas do centro, da periferia e da semiperiferia (Chase-Dunn; Inoue; Alvarez; Niemeyer, 2008).

Aqueles oriundos da periferia estavam em menor número, tinham mais idade e, em geral, eram homens. Além disso, os participantes da 
periferia tendiam a estar vinculados a ONGs patrocinadas externamente, mais do que a organizações do movimentos sociais autofinanciadas e a sindicatos, pois as ONGs têm maior acesso a financiamento para viagens. Os respondentes do sul global foram significativamente mais propensos do que os do norte a mostrarem-se céticos em relação à criação ou à reforma de instituições políticas mundiais, e favoráveis à abolição de instituições globais.

Tal ceticismo decorre, provavelmente, da experiência histórica, de povos externos ao centro, com o colonialismo e com instituições de âmbito global que declaram estar operando segundo princípios universais de justiça, mas cujas ações ou não resolveram os problemas ou os agravaram. Esses "novos abolicionistas" vêm questionando fortemente tanto as instituições globais existentes como aqueles que pretendem reformá-las ou substituí-las.

\section{Formação de um Partido Global e os Desafios da Democracia Global}

A perspectiva dos sistemas-mundo sustenta que a hierarquia global centro-periferia constitui uma estrutura de fundamental importância para se entender e explicar a história mundial e as trajetórias específicas de países e regiões. A hierarquia global se reproduz ao longo do tempo, no sentido de que, apesar de haver certa mobilidade vertical, é difícil deslocarse para cima ou para baixo. A semiperiferia, composta de grandes estados e sociedades nacionais com níveis intermediários de desenvolvimento, é uma zona importante, pois é onde as inovações que alteram tecnologias e formas de organização tendem a ser implementadas (e, às vezes, inventadas). É uma zona fecunda, que produz mudanças estruturais e evolucionárias. Esta é a hipótese do desenvolvimento semiperiférico (ChaseDunn; Hall, 1997, cap. 5). A luta das elites para ascender na hierarquia e 
permanecer no topo exige estratégias hegemônicas que incorporem parte dos que não são elite em projetos de desenvolvimento, mas a resistência daqueles dos estratos inferiores à dominação e à exploração opõe aos projetos hegemônicos novas estratégias contra-hegemônicas de proteção e democratização (ver p.ex., Monbiot, 2003). Sustentamos, aqui, que essa luta sistêmica centro-periferia tem sido um mecanismo importante de mudança social na história mundial, e que ela irá conformar as lutas atuais e futuras envolvendo governança global.

O estado nacional, por muito tempo o locus mais significativo da tomada de decisão política e ponto focal de identidade dos povos, tem sido afrontado, nessas funções tradicionais, pelas organizações internacionais, especialmente corporações multinacionais, organismos de governança regional como a União Europeia, e outras instituições de governança global como a Organização Mundial do Comércio (OMC), o Banco Mundial, e o Fundo Monetário Internacional (FMI) (Markoff 1996). Tanto as elites como os movimentos sociais buscam influenciar a formulação de políticas em múltiplas escalas geográficas; de modo crescente, eles vêm estabelecendo conexões entre os problemas locais e nacionais e aqueles de ordem global, e ampliando sua atuação em âmbito mundial.

Muitos observadores apontam que as instituições de governança global exibem um notório déficit democrático (p. ex., Stiglitz, 2002). Tais instituições carecem de ramos legislativos democraticamente nomeados, de ouvidorias e de mecanismos formais de avaliação das políticas (Scholte 2004, p.211). Scholte (2004) aponta que as relações entre os governos nacionais e as agências de governança global têm fluído principalmente por intermédio de tecnocratas não eleitos que carecem de qualquer vínculo direto com os cidadãos e que os governos nacionais têm concedido aos organismos supraestatais consideráveis prerrogativas em atividades operacionais livres de controle (Scholte 2004, p. 212). Em vista da percepção 
disseminada de tal déficit democrático, não são de surpreender os esforços coletivos de movimentos sociais e ONGs para reconquistar influência política (Smith 2008; Scholte 2004). As elites, do mesmo modo, e particularmente na semiperiferia, têm questionado o papel dominante exercido pelos representantes das nações centrais nas instituições de governança global existentes e demandado a reestruturação das mesmas.

Diversos acadêmicos e ativistas argumentam que a democracia de âmbito mundial requer uma reforma das instituições de governança global e, possivelmente, mesmo a formação de um governo mundial democrático, a fim de melhor regular a economia internacional para que esta seja mais eficaz na resposta às necessidades públicas (Patomaki; Teivainen 2004; Held; McGrew 2002). Outros, no entanto, sustentam que as instituições de governança global devem, simplesmente, ser abolidas.

Muitos vêem o FSM como um instrumento importante na preparação do público para participar ativamente e exercer influência sobre as instituições de governança global. Smith e Wiest (2012), por exemplo, argumenta que o FSM é um alicerce para um sistema de governo global mais democrático, pois possibilita aos cidadãos de muitos países desenvolverem valores e preferências compartilhados, a aperfeiçoar suas análises e estratégias, e aprimorar suas habilidades no diálogo transnacional. Patomaki e Teivainen (2004, p.151) sugerem que o FSM forma um amplo grupo de opinião do qual partidos globais poderiam emergir e exercer influência sobre a política mundial. A última grande onda de formação de um partido global de proletariado (não elite) ocorreu durante e após a revolução mundial de 1917, quando o COMINTERN, a Terceira Internacional, reuniu representantes de partidos comunistas nacionais, bem como de sindicatos e de organizações de mulheres e de jovens em imensos congressos anuais realizados em Moscou, no início dos anos 1920. Desde então, criaram-se algumas organizações formais de partidos inter- 
nacionais, mas estas têm desempenhado um papel pouco relevante na governança global (Patomaki; Teivainen 2007).

\section{A Revolução Mundial de 20xx}

Como já mencionado, a democracia é um conceito controverso, mas tornou-se o principal discurso legitimizador, seja para apoio ou enfraquecimento das estruturas de governo contemporâneas. No âmbito global, enquanto as estruturas de governança existentes são objetos de crítica, novos desafios exigem ação coordenada em escala mundial. Grandes contingentes de pessoas sentem que foram deixados de fora dos milagres das mudanças tecnólogicas, ao passo que outras vêem as novas tecnologias como símbolos de dominação. Ao mesmo tempo, custos de comunicação em rápido declínio possibilitam que amplas redes populares organizem campanhas transnacionais, as quais têm desafiado as principais instituições de governança global, especialmente o G-8, o Banco Mundial, o Fundo Monetário Internacional e a Organização Mundial do Comércio.

O que se observa é a emergência de um corpo político global em que não-elites, de modo crescente, participam diretamente da política mundial. Este não é um fato inteiramente novo. Partidos políticos globais como as Primeira, Segunda e Terceira Internacionais têm desafiado os poderes constituídos desde o século 19. Não obstante, um número crescente de ativistas vem "mudando de escala" para o nível global, ante a pouca eficácia de mobilizações locais ou nacionais no confronto aos problemas de desigualdade global e de degradação ambiental (Reitan, 2007). Esta transnacionalização dos movimentos sociais tem sido muito facilitada pela Internet. Depois do levante dos Zapatistas, no sul do México, em 1994, grandes números de jovens na América no Norte, na Europa e, logo, na América do Sul e na Ásia mobilizaram uma rede des- 
centralizada de grupos locais simpatizantes que ficou conhecida como Ação Global dos Povos. Em 2001, ativistas que infrutiferamente haviam buscado direito de voz no Fórum Econômico Mundial formaram o Fórum Social Mundial como um espaço aberto aos movimentos que se opõem ao neoliberalismo. A Primavera Árabe de 2011, o Verão da Europa, o Outono do Occupy Movement e os contínuos movimentos anti-austeridade são um prolongamento da Revolução Mundial de 20xx.

Esses acontecimentos têm suscitado novas questões relativas à legitimidade de ativistas que reivindicam representar os pobres e oprimidos. Como legitimar tal reivindicação? No âmbito de "movimento dos movimentos", esta se revelou uma questão controversa. Cantores populares politicamente engajados, bem como ONGs com staff profissional e financiamento governamental e fundações afirmam representar os interesses dos grupos pobres e oprimidos. A Via Campesina, uma aliança intercontinental de pequenos agricultores, vetou a participação de não-agricultores em seu grupo de tomada de decisões, por perceber que as ONGs, arbitrariamente, estavam dominando as agendas. Mas mesmo organizações baseadas em movimentos sociais de base têm problemas de legitimidade. Todos os participantes foram consultados? Quem decide sobre quem é incluído e quem é excluído? As noções de democracia participativa e organização de base amplamente aceitas por boa parte do movimento pela justiça global favorecem os líderes que "servem à comunidade". Mas quem definiu a comunidade? Foi permitido a todos os membros opinarem? Democracia é uma noção que pode ser utilizada para criticar tanto os ativistas como os poderes estabelecidos.

As tecnologias de comunicação há muito têm sido importantes para facilitar autoridade e hierarquia, e para mobilizar os confrontos à autoridade que levaram ao desenvolvimento da governança global. E essa série de processos continua. A Internet torna possível um espectro muito mais 
amplo de comunicação e colaboração públicas do que jamais existiu. Os ultrademocratas são os mais motivados e mais impelidos por seus próprios princípios a aproveitar as novas tecnologias da informação e desenvolver novas formas de facilitar a colaboração e tomada de decisão em grupo.

\section{Participação Popular em Mobilizações Globais}

A exclusão digital ainda constitui um importante fator limitador da capacidade das populações pobres e das rurais de acessar a Internet (Netchaeva 2002). Ainda assim, em quase todas as cidades do mundo, hoje, existe uma LAN house. Além disso, operadoras de telefone celular possibilitam, mesmo àqueles que não sabem ler, falar com pessoas distantes. À medida que computadores de bolso de acesso sem fio (como o iPod Touch) tornam-se menos caros, a exclusão digital tenderá a diminuir, limitando-se aos estratos mais vulneráveis da humanidade. Não se devem ignorar os que ainda ficarão excluídos da rede global, mas esses serão, ao final, apenas uma pequena parcela da população mundial.

Encontros globais, como aqueles realizados pelo Fórum Social Mundial, envolvem viagens intercontinentais por parte de um grande número de pessoas que participam desses eventos. Tais encontros são caros, tanto em termos financeiros como de carbono. Uma alternativa muito mais econômica e limpa a deslocar pessoas por via aérea de um continente a outro para comunicarem-se pessoalmente está emergindo nos mundos digitais interativos em 3-D.

\section{Colaboração e Tomada de Decisão Públicas por meio Virtual}

Uma solução é o usar ainda mais a Internet. A comunicação virtual nunca substituirá completamente os encontros presenciais. Mas a emer- 
gência de mundos virtuais interativos tridimensionais pode ser utilizada para expandir enormemente a participação pública na governança global democrática.

Encontros em mundos virtuais tridimensionais podem permitir às pessoas do sul global elaborar estratégias de grupo e coordenar ações, sem ter de viajar para reuniões distantes. No momento, a melhor plataforma disponível para tais encontros é a Second Life, uma comunidade virtual desenvolvida pelos próprios participantes (Ondrejka, 2005). A economia de poder conduzir interações em grupo entre indivíduos distantes, em cenários que podem ser alterados de modo que esses se sintam mais confortáveis, anuncia um grande futuro para reuniões desse tipo.

Organizadores políticos já se instalaram na Second Life. A Diplomacy Island (Ilha da Diplomacia) é um local disponível para reuniões, embora o estilo desse ambiente seja desenhado para o conforto de diplomatas e representantes de governos. Commonwealth Island (Ilha da Comunidade) é um local de reuniões para ONGs e movimentos sociais. Possui espaços para reuniões de pequenos, médios e grandes grupos que são mais acolhedores para ativistas dos movimentos pela justiça global. Outra tecnologia da internet que pode facilitar tomadas de decisão participativas e horizontais é o software de processo Wiki ${ }^{\mathrm{NT}}$. Ao invés de um encontro intelectual de um pequeno grupo em um hotel, para formular um manifesto como o Apelo de Bamako (Bamako Appeal, 2006), documentos podem ser produzidos coletivamente e democraticamente por um grande número de pessoas situadas em distintos continentes.

\footnotetext{
NT Um Software Wiki é um tipo de software colaborativo para executar sistemas wiki. Permite a edição coletiva dos documentos usando um sistema simples, sem que o conteúdo tenha que ser revisto antes da sua publicação. A Wikipédia é um exemplo deste sistema (http: pt.wikipedia.org/wiki/Software_wiki).(Nota de tradução)
} 


\section{O Partido Mundial e o Duplo Poder}

Como se mencionou anteriormente, a poliarquia no âmbito nacional não satisfaz. Concordamos com os críticos da poliarquia em que esta não constitui o melhor dos mundos. Sustentamos que a verdadeira democracia deve abordar os problemas da riqueza e da propriedade, ao invés de defini-los como questões que ultrapassam os limites do discurso político. Além disso, pode-se, também, aprender muito com as experiências de propriedade coletiva realizadas em países comunistas e socialistas ao longo do século 20. A propriedade estatal, mesmo quando o estado é efetivamente democrático, cria graves entraves econômicos, em razão do problema das "restrições orçamentárias fracas". Grandes firmas precisam competir nos mercados umas com as outras, mas, mais importante que isso, é que elas devem competir por financiamento, mostrando que são capazes de gerar lucros. Merece destaque o modelo de John Roemer (1994) de socialismo de mercado, no qual as ações de grandes empresas são distribuídas a todos os cidadãos adultos que, então, investem suas ações no mercado de capitais, a principal fonte de capital para grandes empresas. Todos os cidadãos recebem um determinado número de ações quando atingem a maioridade e, quando falecem, suas ações revertem ao bem público. Assim, não há herança de propriedade corporativa, embora a propriedade pessoal possa ser herdada. As firmas, grandes e pequenas, produzem para os mercados, e o trabalho é recompensado em mercados de trabalho competitivos. Firmas de pequeno porte podem ser de propriedade privada. Este tipo de socialismo de mercado equipara rendas, embora algumas desigualdades, devidas a diferentes habilidades, seguirão existindo. A economia ainda será uma economia de mercado, mas o estado democrático garantirá segurança e propriedade, e controlará a redistribuição de ações corporativas entre gerações. 
Este modelo de socialismo público incentiva a mudança tecnológica e a eficiência, sem criar e ampliar desigualdades. Funcionaria bem, especialmente nos países centrais para os quais Roemer (1994) o idealizou. Contudo, quando consideramos a economia global, há certos problemas que não são abordados no modelo de Roemer (1994). O principal problema na economia global são as enormes diferenças de produtividade entre a mão de obra central e a periférica. Por essa razão, os padrões de trabalho fixados nos acordos econômicos internacionais são um anátema para os trabalhadores e sindicatos de países periféricos. Eles funcionam como acordos protecionistas para os trabalhadores do centro e debilitam a capacidade dos trabalhadores da periferia global de produzir bens e vendê-los nos mercados centrais. A solução para isso seria elevar o nível de produtividade da mão de obra periférica. A democracia global deverá construir instituições que possam fazê-lo.

Esta é a razão por que precisamos democratizar e dotar de poder as instituições de governança global, inclusive o Banco Mundial e o Fundo Monetário Internacional. Movimentos que buscam abolir essas instituições financeiras internacionais, porque são símbolos do capitalismo global, precisam ou reformá-las radicalmente, ou conceber instrumentos melhores, que possam lidar com a questão das desigualdades centro/periferia. Socialismo de mercado no centro não será suficiente. Um movimento por democracia econômica no centro precisa também mobilizar por democracia econômica em âmbito global.

É mais provável que um apoio significativo tanto para regimes nacionais mais democráticos como para instituições socialistas globais venha a gerar-se na semiperiferia. Espera-se que parte dos maiores esforços para democratizar o capitalismo global virá de movimentos e de regimes socialistas democráticos que emergem em países semiperiféricos. Como em épocas anteriores, países semiperiféricos têm as "vantagens do atraso" 
- ainda não estão fortemente investidos de instituições e tecnologias políticas e organizacionais - e, portanto, têm espaço de manobra e recursos para investir em novas instituições.

Países periféricos também poderiam fazê-lo, mas esses dependem em maior grau do centro e não têm capacidade de mobilizar recursos suficientes para superar tal dependência. A Bolívia, governada por Evo Morales, pode vir a ser uma exceção. A semiperiferia, especialmente os grandes países semiperiféricos como México, Brasil, Argentina, Índia, Indonésia, China e Venezuela, desfruta de oportunidades que nem países do centro nem os periféricos têm. Se um regime democrático socialista é capaz de alcançar o poder de estado por meios legais, e se este regime tem a vontade política para mobilizar os setores populares em favor de um socialismo democrático, uma experiência de socialismo de mercado do tipo roemeriano poderia ser realizada. Regimes deste tipo podem ter surgido na chamada "Maré Rosa" (Pink Tide) na América Latina. Outros, provavelmente, vão emergir, já que a opção de dobrar-se ante megacorporações e operadores financeiros mostra-se desgastada.

Os países semiperiféricos menores (Coreia do Sul, Taiwan, África do Sul) também podem optar pelo socialismo democrático, embora seja de esperar que estes só poderão fazê-lo depois das primeiras tentativas nos países semiperiféricos maiores.

Tais regimes socialistas democráticos semiperiféricos são os entes organizacionais que poderão forjar os vínculos entre os movimentos anti-sistêmicos globais, e estabelecer uma rede para criar as instituições do socialismo global. A globalização a partir da base e a formação de instituições globais socialistas terão de ser facilitadas por uma confederação flexível de cidadãos do mundo, organizada como uma rede política democrática. Adotamos aqui a denominação atribuída a tal confederação por Warren Wagar (1996) - o Partido Mundial. Mas este não é um partido no velho 
sentido da Terceira Internacional - um partido de vanguarda do mundo proletário. Ao contrário, o Partido Mundial que propomos seria uma rede de pessoas e de representantes de organizações populares de todo o mundo que concordam em cooperar na criação de uma comunidade global coletivamente racional. O Partido Mundial estará aberto a pessoas de diferentes nações e religiões e buscará criar as bases institucionais para uma sociedade mundial culturalmente pluralista, socialmente justa e ecologicamente sustentável - uma democracia global.

\section{Referências}

ARRIGHI, Giovanni. The Long Twentieth Century: Money, Power and the Origins of Our Time. London: Verso, 1994.

ARRIGHI, Giovanni. Adam Smith in Beijing: Lineages of the 21st Century. London: Verso, 2007.

ARRIGHI, Giovanni; HOPKINS, Terence; WALLERSTEIN, Immanuel. Antisystemic Movements. London: Verso, 1989.

ARRIGHI, Giovanni; SILVER, Beverly. Chaos and Governance in the Modern World-System: Comparing Hegemonic Transitions. Minneapolis: University of Minnesota Press, 1999.

BAMAKO Appeal. [S.I.]: Monthly Review, 2006. Disponível em: <http://mrzine. monthlyreview.org/bamako.html>. Acesso em: 23 Feb. 2012.

BECK, Ulrich. Power in the Global Age. Malden, MA: Polity Press, 2005.

BOLI, John; THOMAS, George. (Eds.) Constructing world culture: international nongovernmental organizations since 1875 . Stanford, CA: Stanford University Press, 1999.

BOLLEN, Kenneth; PAXTON, Pamela. Democracy before Athens. In: MANUS, Midlarsky. (Ed.) Inequality, Democracy and Economic Development. Cambridge: Cambridge University Press, 1997. p. 13-44.

BOSWELL, Terry; CHASE-DUNN, Christopher. The Spiral of Capitalism and Socialism: Toward Global Democracy. Boulder: Lynne Rienner, 2000a.

BOSWELL, Terry; CHASE-DUNN, Christopher. From state socialism to global democracy: the transnational politics of the modern world-system. In: HALL, Tho- 
mas (Ed.) A World-Systems Reader: New Perspectives on Gender, Urbanism, Cultures, Indigenous Peoples, and Ecology. Lanham, MD: Rowman and Littlefield, 2000b. p. 289-306.

BUNKER, Stephen; CICCANTELL, Paul. Globalization and the Race for Resources. Baltimore, MD: Johns Hopkins University Press, 2004.

BYRD, Scott. The Porto Alegre Consensus: Theorizing the Forum Movement. Globalizations. v. 2, n. 1, p. 151-163, 2005.

CHASE-DUNN, Christopher. Sociocultural evolution and the future of world society. World Futures, v. 63, n. 5-6, p. 408-424, 2007.

CHASE-DUNN, Christopher; HALL, Thomas. Rise and Demise: Comparing WorldSystems. Boulder, CO: Westview, 1997.

CHASE-DUNN, Christopher; Kawano, Yukio; Brewer, Benjamin. Trade globalization since 1795: waves of integration in the world-system. American Sociological Review, v. 65, n.1, p. 77-95, Feb. 2000.

CHASE-DUNN, Christopher; INOUE, Hiroko; ALVAREZ, Alexis; NIEMEYER, Richard. Global State Formation In World Historical Perspective. In: ATASOY, Yildiz. (Ed). World Hegemonic Transformations: The State and Crisis in Neoliberalism. London: Routledge, 2008.

DAVIS, Mike. Late Victorian Holocausts. London: Verso, 2001.

DELLA PORTA, Donatella. Making the polis: social forums and democracy in the global justice movement. Mobilization, v. 10, n. 1, p. 73-94, 2005.

DELLA PORTA, Donatella; ANDRETTA, Massimilano; MOSCA, Lorenzo; REITER, Herbert. Globalization From Below. Minneapolis: University of Minnesota Press, 2006.

GAT, Azar 2006 War in Human Civilization. New York: Oxford University Press.

HELD, David; MCGREW, Anthony. Globalization/Antiglobalization. Cambridge: Blackwell, 2002.

JOHNSON, Chalmers. Blowback: The Costs and Consequences of American Empire. New York: Henry Holt, 2000.

KECK, Margaret; SINKINK, Kathryn. Activists Beyond Borders: Advocacy Networks in International Politics. Ithaca: Cornell University Press, 1998.

$\mathrm{KIRCH}$, Patrick. The Evolution of Polynesian Chiefdoms. Cambridge: Cambridge University Press, 1984.

MARKOFF, John. Waves of Democracy: Social Movements and Political Change. Thousand Oaks, CA: Pine Forge Press, 1996. 
MARKOFF, John. Globalization and the future of democracy. In: CHASE-DUNN, Christopher; BABONES, S. Global Social Change. Baltimore: Johns Hopkins University Press, 2006. p. 336-362.

MODELSKI, George; THOMPSON, William. Leading Sectors and World Powers: The Coevolution of Global Politics and Economics. Columbia, SC: University of South Carolina Press, 1996.

MOGHADAM, Valentine. Globalizing Women. Baltimore, MD: Johns Hopkins University Press, 2005.

MONBIOT, George. Manifesto for a New World Order. New York: New Press, 2003.

MURPHY, Craig. International Organization and Industrial Change: Global Governance since 1850. New York: Oxford, 1994.

NETCHAEVA, Irina. E-government and E-democracy: A comparison of the opportunities in the North and South. Gazette, v. 64, n. 5, p. 467-477, 2002.

ONDREJKA, Cory. Changing realities: user creation, communication and innovation in digital worlds. Linden Lab White Papers. 2005 Disponível em: < http:// lindenlab.com/whitepapers/Changing_Realities_Ondrejka.pdf $>$. Acesso em: 15 Mar. 2012.

O'ROURKE, Kevin; WILLIAMSON, Jeffrey. Globalization and History: The Evolution of a $19^{\text {th }}$ Century Atlantic Economy. Cambridge, MA: MIT Press, 1999.

PATOMAKI, Heikki; TEIVAINEN, Teivo. The World Social Forum: an open space or a movement of movements. Theory, Culture and Society, v. 21, n. 6, p. 145154, Dec. 2004.

PATOMAKI, Heikki; TEIVAINEN, Teivo. Researching global political parties. In: SEHM-PATOMAKI, Katarina; ULVILA, Marko. (Eds.) Global Political Parties. London: Zed Press, 2007. p. 92-113.

REITAN, Ruth. Global Activism.London: Routledge, 2007.

REUVENY, Rafael; THOMPSON, William R. (eds.). North and South in the World Political Economy. Malden, MA: Blackwell, 2008

ROBINSON, William. Promoting Polyarchy: Globalization, US Intervention and Hegemony. Cambridge: Cambridge University Press, 1996.

ROBINSON, William. A Theory of Global Capitalism. Baltimore: MD. Johns Hopkins University Press, 2004.

ROEMER, John. A Future for Socialism. Cambridge, MA: Harvard University Press, 1994. 
SASSEN, Saskia. Territory, Authority, Rights: From Medieval to Global Assemblages. Princeton, NJ: Princeton University Press, 2006.

SCHOLTE, Jan Aart.Civil society and democratically accountable global governance. Government and Opposition, v. 39, n. 2, 2004, p. 211-233.

SHIVA, Vandana. Earth Democracy. Cambridge, MA: South End Press, 2005.

SMITH, Jackie. Social Movements for Global Democracy. Baltimore, MD: Johns Hopkins University Press, 2008.

SMITH, Jackie; KARIDES, Marina; BECKER, Marc; BRUNELLE, Dorval; CHASEDUNN, Christopher; ICAZA, Rosalba; JURIS, Jeffrey; MOSCA, Lorenzo; DELLA PORTA, Donatella; REESE, Ellen; SMITH, Peter Jay; VÁSZUEZ, Rolando. The World Social Forum and the Challenges of Global Democracy. Boulder, CO: Paradigm Publishers, 2007.

SMITH, Jackie; WIEST, Dawn. Social Movements in the World-System. New York: Russell Sage, 2012.

STIGLITZ, Joseph Eugene. Globalization and its Discontents. New York; Norton, 2002.

TARROW, Sidney. The New Transnational Activism. Cambridge: Cambridge University Press, 2005.

TILLY, Charles Democracy. Cambridge: Cambridge University Press, 2007.

WAGAR, Walter Warren. Toward a praxis of world integration, Journal of WorldSystems Research, v. 2, n. 1, 1996 Disponível em: <http://csf.colorado.edu/ wsystems/jwsr.html>. Acesso em: 27 Mar. 2012 